\title{
Modified Pectin as Imprinting Substrate to Immobilize Pectinase via Both Adsorption and Crosslinking
}

\author{
Jing Xiao, ${ }^{\mathrm{a}, \mathrm{b}, *}$ Ziyuan Li, ${ }^{\mathrm{a}, \mathrm{b}}$ Jian Sun, ${ }^{\mathrm{a}, \mathrm{b}}$ and Qinzheng Yang a,b,* \\ A broad-spectrum substrate-imprinted adsorption and crosslinking double \\ immobilized pectinase (SDP) was prepared using a universal modified \\ pectin obtained through enzymatic hydrolysis as the imprinting substrate. \\ Its structure was characterized by infrared spectroscopy, circular \\ dichroism, and scanning electron microscopy. The results showed that 1) \\ cross-linking increased the Schiff base in SDP, 2) immobilization barely \\ changed the secondary structure such as $\alpha$-helix and $\beta$-sheet of SDP, and \\ 3 ) adhesives were evenly distributed on the surface after immobilization. \\ Studies on the enzymatic properties of SDP showed that the substrate \\ imprinting significantly improved heat resistance and neutralization \\ resistance of SDP. For example, the relative activity of SDP at 35 to $75^{\circ} \mathrm{C}$ \\ and at $\mathrm{pH} 4.4$ to 6.5 was $5 \%$ and $15 \%$ more than that of the adsorption \\ and crosslinking double immobilized pectinase (DP), respectively. In \\ addition, after 8 cycles of use, the relative enzyme activity of SDP still \\ reached 39.5\%. Moreover, use of SDP decreased the cation demand in \\ whitewater by $10 \%$ compared with DP. Overall, the use of a broad- \\ spectrum substrate for imprinting to obtain SDP provides a new idea and \\ method for using pectinase in in complex systems such as juice \\ clarification and wastewater treatment.
}

Keywords: Pectinase; Immobilized; Substrate-imprinted; Whitewater treatment

Contact information: a: State Key Laboratory of Biobased Material and Green Papermaking, Qilu University of Technology, Shandong Academy of Sciences, Jinan, 250353, Shandong, P. R China;

$b$ : Department of Bioengineering, Qilu University of Technology, Shandong Academy of Sciences, Jinan, 250353, Shandong, P. R China; *Corresponding authors: xiaojing8168@163.com; yqz@qlu.edu.cn

\section{INTRODUCTION}

Pectinase is a hydrolytic enzyme that can degrade pectic substances and primary constituents of cell walls into basic monomeric units. It is used frequently in various industries for fruit juice extraction, water and wastewater treatment, and paper bleaching (Esawy et al. 2013). The activity of free pectinase (FP) decreases after repeated use or under high temperature, as well as in strongly acidic or alkali conditions, which limits its industrial application. Using immobilization techniques such as adsorption, embedding, covalent and ionic bonding, and crosslinking can improve its stability and reuse ability (Wu et al. 2014; Ramirez et al. 2016). However, enzymes are often randomly immobilized using these methods, resulting in reduction or loss of enzyme activity (Liu et al. 2010). Therefore, it is necessary to find new immobilization methods to reduce the adverse effects on enzyme activity during immobilization, protect enzyme active center, and allow enzyme reuse in specific environments.

Substrate imprinting is a technique developed based on molecular imprinting technology. It could change the conformation of enzymes via interaction between enzymes and substrates. Imprinting substrates on enzymes could avoid inactivation of enzymes 
during immobilization. Molecular imprinting technology was originally used as an artificial biotemplate technique to mimic antibody-antigen interactions to construct template polymers with specific selective recognition sites (Chaput et al. 2012; Rehman et al. 2014; Gaio et al. 2017). Later, it was used to imprint and immobilize enzymes. Ohmiya et al. (1975) obtained glucoamylase with high activity, stability, and repeatability by first immobilizing it onto polyacrylic acid nitride in the presence of a substrate and then crosslinking the multimeric-enzyme complex with hydroxylamine. Compared with glucoamylase, industrial pectinase is an enzyme with low substrate specificity. When imprinted with a single substrate, the retained enzyme activity can only be directed to a single substrate, and the activity of the non-imprinted pectinase in the process of enzyme immobilization will still be affected (Kashyap et al. 2001; Wu et al. 2013). Studying the immobilization of broad-spectrum enzymes by selecting a universal substrate has important significance for improving the catalytic performance of industrial composite enzymes and their commercial application prospects.

In this paper, modified pectin was selected as a universal substrate for pectinase immobilization, and it was used to immobilize pectinase via the substrate imprinting technique. The obtained immobilized enzyme was subjected to structural tests using Fourier transform infrared spectroscopy (FT-IR), circular dichroism spectra (CD spectrum), and scanning electron microscopy (SEM), and the properties of the immobilized enzyme and its application in whitewater were examined. This technology has broad application prospects for improving the catalytic performance of pectinase to meet the needs of current large-scale production.

\section{EXPERIMENTAL}

Preparation of Adsorption-Crosslinking Double Immobilized Pectinase (DP) Adsorption-crosslinking double immobilized pectinase (DP) was prepared following the below steps. Chitosan powder (4.0 g, deacetylation degree $\geq 95 \%)$ was dissolved in $100 \mathrm{~mL}$ of $5 \%(\mathrm{v} / \mathrm{v})$ acetic acid solution. The chitosan-acetic acid solution was added dropwise into $200 \mathrm{~mL}$ mixture of 3 parts $2 \mathrm{M} \mathrm{NaOH}$ and 1 part absolute ethanol. After incubation at room temperature for $3 \mathrm{~h}$, the liquid was removed by vacuum filtration, and the products were washed to neutrality to obtain chitosan microspheres with a diameter of $2 \mathrm{~mm}$. The chitosan microspheres were crosslinked with $0.05 \%$ glutaraldehyde solution for $1 \mathrm{~h}$ and washed with distilled water to remove residual glutaraldehyde. The prepared wet cross-linked chitosan microsphere carriers were added into $20 \mathrm{~mL}$ of pectinase solution $\left(1 \mathrm{~g} / \mathrm{L}\right.$, pectin hydrolase, $10000 \mathrm{U} / \mathrm{g}$ ) and incubated at $25{ }^{\circ} \mathrm{C}$ for $3 \mathrm{~h}$ to allow adsorption. The mixture was filtered and washed thoroughly, and the products were stored at $4{ }^{\circ} \mathrm{C}$ after lyophilization.

\section{Preparation of Substrate-Imprinted Adsorption-Crosslinking Double Immobilized Pectinase (SDP)}

Substrate-imprinted adsorption-crosslinking double immobilized pectinase (SDP) was prepared using the following steps. First, $50 \mathrm{~mL}$ of orange pectin substrate $\mathrm{S}(5 \mathrm{~g} / \mathrm{L}$, galacturonic acid, $\geq 74 \%)$ was mixed with $1 \mathrm{~L}$ of pectinase solution $(1 \mathrm{~g} / \mathrm{L}$, ibid $)$ and incubated at $50{ }^{\circ} \mathrm{C}$ in a water bath for certain period of time. The mixture was centrifuged for $15 \mathrm{~min}$ at $8000 \mathrm{rpm}$, and the supernatant was freeze-dried. The modified pectin $(5 \mathrm{mg})$ was mixed with $20 \mathrm{~mL}$ of pectinase solution $(1 \mathrm{~g} / \mathrm{L}$, ibid $)$. All of the prepared wet cross- 
linked chitosan microsphere carriers were added into $20 \mathrm{~mL}$ of pectinase solution $(1 \mathrm{~g} / \mathrm{L}$, ibid) and incubated at $25{ }^{\circ} \mathrm{C}$ for $3 \mathrm{~h}$ to allow adsorption. The mixture was filtered and washed thoroughly, and the products were stored at $4{ }^{\circ} \mathrm{C}$ after lyophilization.

\section{Structural Characterization of Immobilized Pectinase}

The samples were characterized using a Hitachi Regulus 8220 scanning electron microscope (Tokyo, Japan) at voltage of $5.0 \mathrm{kV}$. In addition, the samples were prepared as $\mathrm{KBr}$ tablets and tested at a Nicolet 10 Fourier transform infrared spectrometer (Massachusetts, America) at 500 to $4000 \mathrm{~cm}^{-1}$. These samples were examined using a Chirascan circular dichroism spectrometer (Shanghai, China) with the scanning range of 300 to $190 \mathrm{~nm}$.

\section{Determination of Enzyme Properties}

Effects of temperature and $\mathrm{pH}$ on the activities of the three enzymes (FP, DP, and SDP)

To explore the effect of temperature on the activity of the three enzyme samples, their activity was measured at $\mathrm{pH} 4.0$ for $1 \mathrm{~h}$ at different temperatures $\left(35^{\circ} \mathrm{C}\right.$ to $\left.75{ }^{\circ} \mathrm{C}\right)$. The activity of pectinase at its optimal temperature was defined as $100 \%$, and used to calculate the relative enzyme activity $(\%)$ at other temperatures.

To explore the effect of $\mathrm{pH}$ on the activity of the three enzyme samples, their activity was measured at $50{ }^{\circ} \mathrm{C}$ for $1 \mathrm{~h}$ at different $\mathrm{pH}(\mathrm{pH} 3.0$ to 6.5). The activity of pectinase under the optimal $\mathrm{pH}$ was defined as $100 \%$ and used to calculate the relative enzyme activity $(\%)$ under other $\mathrm{pH}$ conditions.

To explore the thermal stability of the three enzyme samples, three pectinase enzymes were incubated at $\mathrm{pH} 4.0$ and different temperatures $\left(20^{\circ} \mathrm{C}\right.$ to $\left.80{ }^{\circ} \mathrm{C}\right)$ for $1 \mathrm{~h}$, and the pectinase activity was measured at $50{ }^{\circ} \mathrm{C}$. The enzyme activity at $20^{\circ} \mathrm{C}$ was $100 \%$, and the relative enzyme activity $(\%)$ at other temperature conditions was calculated.

\section{Determination of kinetic parameters of the three enzymes (FP, DP, and SDP)}

To determine kinetic parameters of the three enzymes, their activity was measured at $50{ }^{\circ} \mathrm{C}$ under $\mathrm{pH} 4.0$ for $1 \mathrm{~h}$ at different substrate concentrations and used to calculate $K_{\mathrm{m}}$ of the three enzymes using Lineweaver-Burk double reciprocal method. Michaelis constant $(\mathrm{Km})$ means the concentration of substrate $(\mathrm{S})$ when the enzymatic reaction reaches half the maximum speed $(\mathrm{Vm})$.

\section{Application of the Three Pectinases (FP, DP, and SDP) in Whitewater Treatment}

A certain amount of pectinase was mixed with $50 \mathrm{~mL}$ of papermaking whitewater and incubated at $50{ }^{\circ} \mathrm{C}$ for $1 \mathrm{~h}$. The galacturonic acid content in papermaking whitewater was measured using the DNS method. The $\mathrm{pH}$ and conductivity of the papermaking whitewater was measured using a $\mathrm{pH}$ meter and conductivity meter, respectively. The cation requirement was determined using the titration method with a standard cationic titration solution PDADMAC (charge density: $1000 \mu \mathrm{eq} / \mathrm{L}$ ) and a PCD streaming current detector. 


\section{RESULTS AND DISCUSSION}

\section{Structural Characterization of SDP}

The infrared spectra of the imprinted substrate modified pectin as well as DP and SDP are shown in Fig. 1a. DP exhibited a stretching vibration of $-\mathrm{C}=\mathrm{O}$ at $1640 \mathrm{~cm}^{-1}$, which is related to the formed Schiff base. In contrast, the corresponding peak was shifted to 1590 $\mathrm{cm}^{-1}$ in SDP with increased intensity. The imprinting substrate MP showed a strong O-H absorption peak at $3300 \mathrm{~cm}^{-1}-3480 \mathrm{~cm}^{-1}$, a vibration absorption peak of $\mathrm{CH}$-in methylene at $1730 \mathrm{~cm}^{-1}$, and a strong-C $=\mathrm{O}$ stretching vibration peak at $1730 \mathrm{~cm}^{-1}$, all of which were weakened or not present in SDP. This may be due to the fact that the structure of SDP tends to be stable at the presence of the imprinting substrate, which facilitates the cross-linking reaction and results in an increased Schiff base. The disappearance and significant decrease of these characteristic peaks of MPs in immobilized SDP after immobilization indicates that the imprinting substrate has been removed and the enzyme activity center is released (Silva et al. 2012; Bustamante-Vargas et al. 2015; Chauhan et al. 2015; Chakraborty et al. 2016; Sojitra et al. 2017).
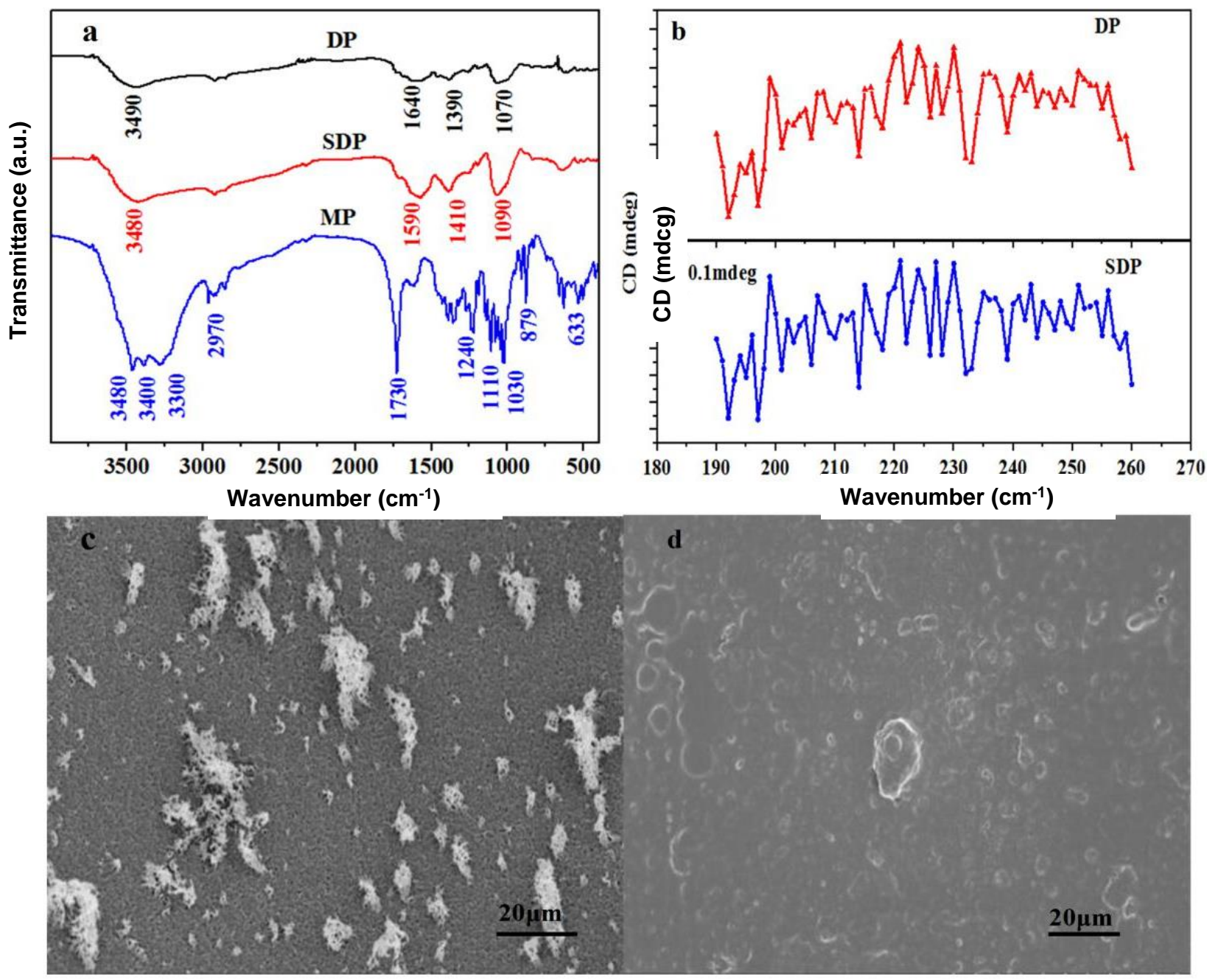

Fig. 1. Infrared spectra of SDP, DP and MP (a), CD spectra of SDP and DP (b), and SEM images of DP (c) and SDP (d) 
The circular dichroism (CD) spectra of DP and SDP are shown in Fig. 1b. The immobilization process caused a conformational change in the secondary structure of the enzymes, showing great fluctuations in the range of $190 \mathrm{~nm}$ to $260 \mathrm{~nm}$. The value of SDP increased by only about $5 \%$ compared with that of DP, suggesting that SDP and DP have similar alpha-helix and beta-sheet structures. This may be related to the catalytic and binding groups in the active center and other essential group outside the active center (tryptophan, etc.). When substrate binds to these groups, the active center of the enzyme is protected, and its structure is stabilized. In addition, the crosslinking increases the content of Schiff base, which is consistent with the results obtained by infrared spectral analysis (Bahrami and Hejazi 2013; Rehman et al. 2013).

Figures 1c and d show the SEM images of chitosan microsphere after addition of DP and SDP, respectively. In Fig. 1c, it is clear that there are many unevenly distributed adhesives on the surface of microspheres. This may be because the pectinase is immobilized on the surface of the DP-adsorbed microspheres, forming enzyme clusters with various sizes. In Fig. 1d, the adhesives on the surface of the SDP-adsorbed microspheres are evenly distributed and have morphology different from that shown in Fig. 1c, indicating that substrate imprinting before immobilization changes the molecular structure of pectinase (Wang et al. 2013) and subsequently alters the morphology of adhesives on the surface of the carrier. Taking together, the increased Schiff base in SDP found in the infrared and CD spectra and the evenly distributed adhesives on the surface of SDP-adsorbed microspheres in SEM images clearly show that the contact area between the immobilized enzyme and the imprinting substrate was increased.

\section{Enzymatic Properties of SDP}

To explore changes in the enzymatic properties of SDP, the ability of FP, DP, and SDP to hydrolyze pectin was determined at $\mathrm{pH} 4.0$ and different temperature conditions or at $50{ }^{\circ} \mathrm{C}$ and different $\mathrm{pH}$ conditions using citrus pectin $\mathrm{S}$ as the substrate. The thermal stability of FP, DP, and SDP was measured. The results in Fig. 2a show that the optimal temperature was $50{ }^{\circ} \mathrm{C}$ for $\mathrm{FP}$ and $60{ }^{\circ} \mathrm{C}$ for DP and SDP. In addition, the relative enzyme activity of SDP was slightly higher than that of DP at $35^{\circ} \mathrm{C}$ to $75{ }^{\circ} \mathrm{C}$ (except at $60{ }^{\circ} \mathrm{C}$ ). This result indicates that the heat resistance of DP and SDP was similar and improved compared with FP because the stabilization effect of the carrier matrix limits the conformational change of pectinase during thermal denaturation. Moreover, higher activation energy makes the substrate easily diffuse to the immobilized enzyme and bind to its binding sites. Imprinting substrate to SDP before immobilization also stabilizes the physicochemical properties of SDP and increases its rigidity, resulting in a slightly lowered heat resistance of SDP than DP (Mai et al. 2016; Rajdeo et al. 2016). However, long-term incubation at higher temperatures can decrease enzyme activity or even inactivate the enzyme; proteins denature at a certain temperature, which ultimately affects their enzymatic activity (Mendes et al. 2011).

The results in Fig. 2b show that the optimal pH of FP, DP, and SDP was pH 3.5, and the trend of relative enzymatic activity at different $\mathrm{pH}$ was similar for these three enzymes, although FP and DP had higher relative activity only at pH 3.0 to 4.0, while SDP maintained a relatively high relative activity at $\mathrm{pH} 3.0$ to 6.5 . Specifically, the relative activity of SDP at pH 4.5 to 6.5 was $15 \%$ higher than that of DP (Lei et al. 2007). Changes in $\mathrm{pH}$ affect the structure and charge of the enzyme activity center as well as the matrix (Rehman et al. 2014). Because the structure of the immobilized enzymes is stable, they are 
less affected by $\mathrm{pH}$ of the reaction solution. Because SDP is subjected to substrate imprinting before immobilization, the remaining activity of SDP after immobilization is high. In addition, the stable chemophysical properties and enhanced rigidity of the active center of SDG improve its resistance to acidic and basic environments.
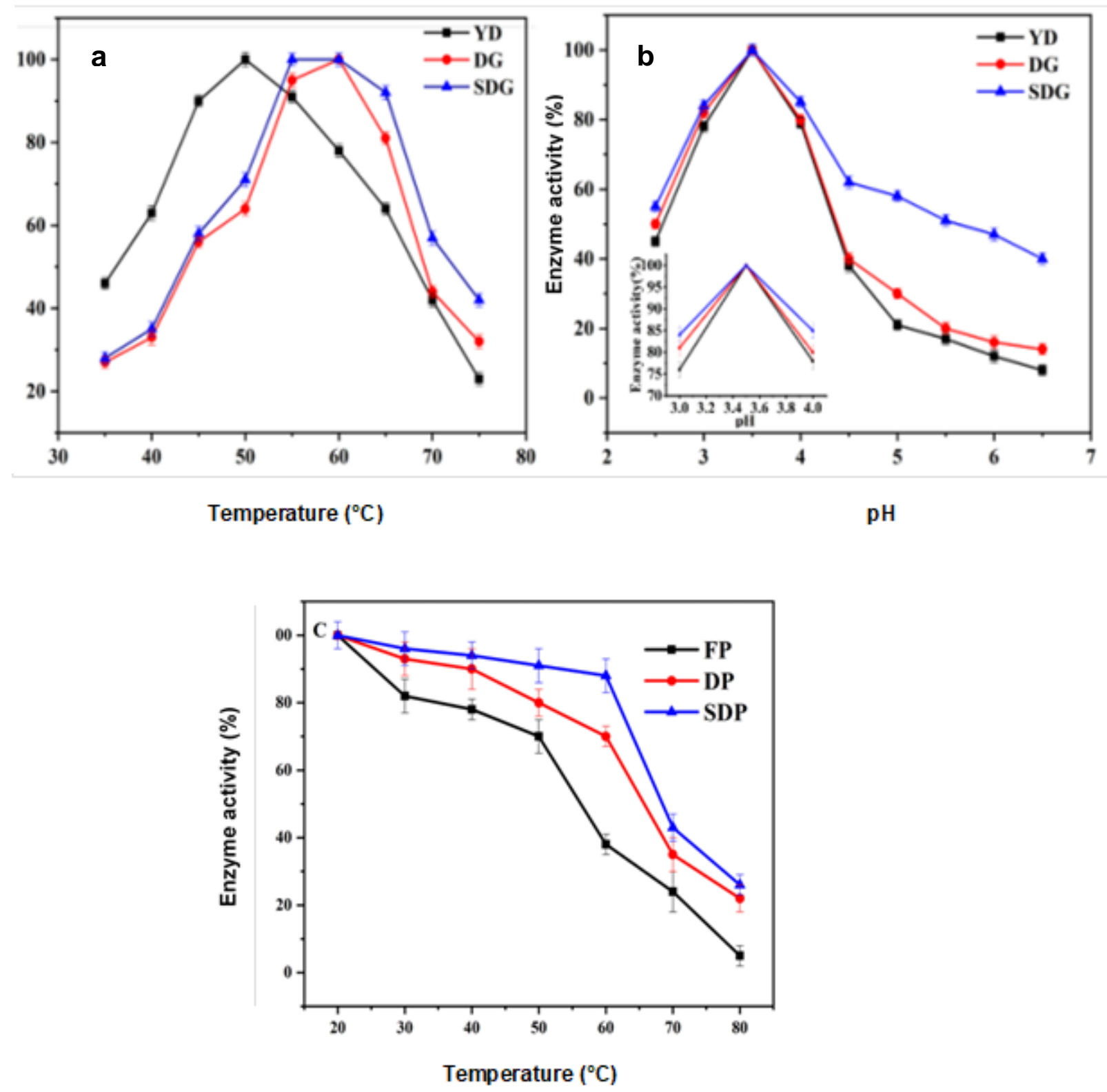

Fig. 2. Effects of temperature (a) and $\mathrm{pH}$ (b) on the activity of FP, DP, and SDP; and effects of FP, DP, and SDP on thermal stability (c)

The thermal stability of FP, DG, and SDG was determined using citrus pectin S as a substrate. The results are shown in Fig. 2c. The relative activity of FP was maintained at $60 \%$ or higher at 20 to $50{ }^{\circ} \mathrm{C}$. DP and SDP maintained high stability at 20 to $60^{\circ} \mathrm{C}$ and 20 $65{ }^{\circ} \mathrm{C}$, respectively. With the increase of temperature, the activities of three enzymes decreased to different degrees. However, the thermal stability of SDG was always higher 
than that of FP and DG, because the high temperature causes the enzyme molecule to be thermally denatured, and the substrate imprinting process enhances the rigidity of the enzyme molecule and improves the thermal stability of the enzyme molecule.

To explore changes in substrate affinity of SDP, the activity of the three pectinases was determined at $50{ }^{\circ} \mathrm{C}$ and $\mathrm{pH} 4.0$ with different substrate concentrations and used to calculate their $K_{\mathrm{m}}$ using the Lineweaver-Burk double reciprocal method. As shown in Fig. $3 \mathrm{a}$, b, and c, the $K_{\mathrm{m}}$ values of FP, DP, and SDP were $9.585 \mathrm{mg} / \mathrm{mL}, 8.901 \mathrm{mg} / \mathrm{mL}$, and $7.854 \mathrm{mg} / \mathrm{mL}$, respectively. The reduced $K_{\mathrm{m}}$ value of SDP indicates that the affinity of SDP to pectin was increased. This may be due to the catalytic ability of pectinase to pectin after substrate imprinting to the enzyme increases the concentration of the intermediate product, making it tend to dissociate into enzyme and product and resulting in a smaller $K_{\mathrm{m}}$. In addition, the enzyme is activated due to the induction of the imprinting substrate, leading to increased affinity of the enzyme to the substrate (Lei and Bi 2007; Liu et al. 2008).
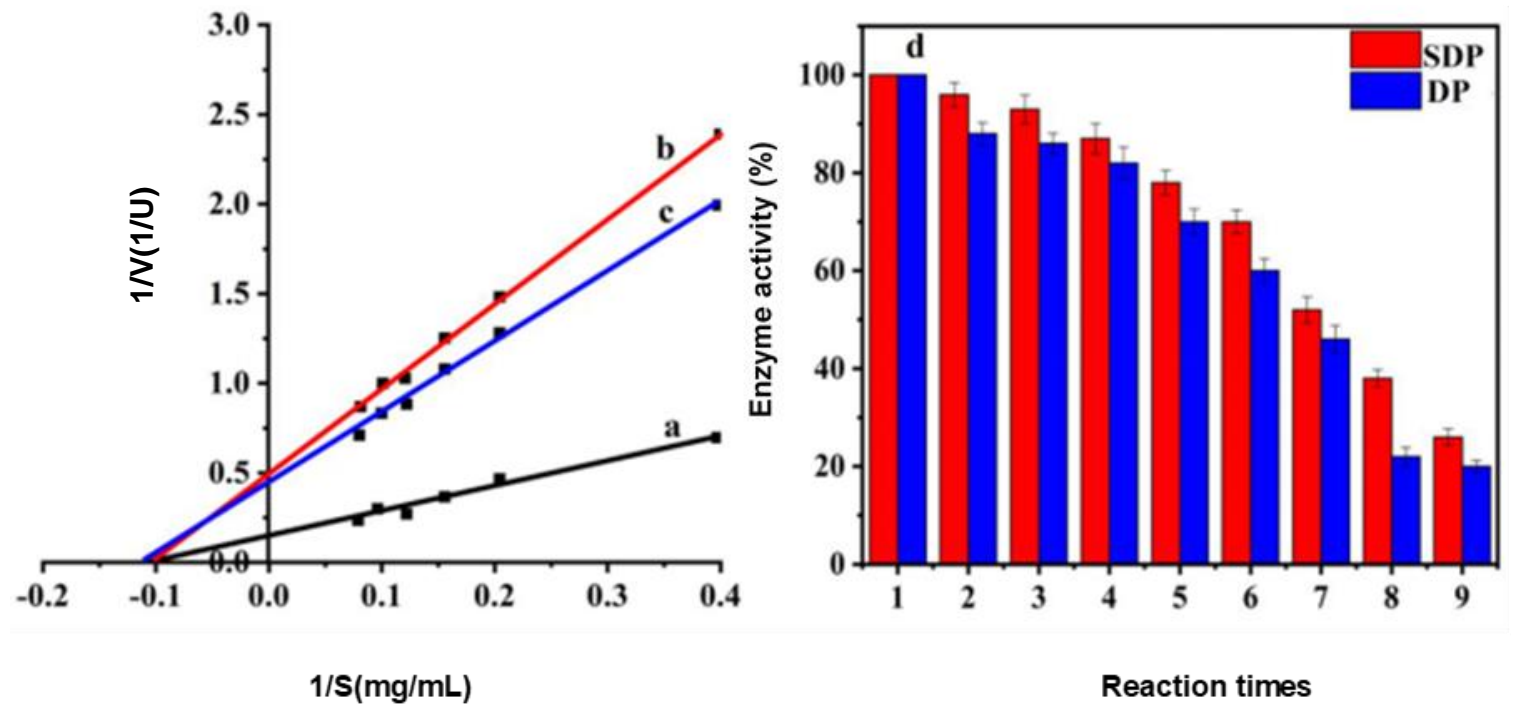

Fig. 3. Lineweaver-Burk double reciprocal plot of YP (a), DP (b) and SDP (c) as well as the activity recovery of DP and SDP after multiple uses (d)

Figure $3 \mathrm{~b}$ shows the operational stability of DP and SDP using citrus pectin S as the substrate. As the number of usage increased, the enzyme activity of SDP and DP decreased. At the 8 and 9 cycles of use, the relative activity of DP decreased to $21.5 \%$ and $19.6 \%$, respectively, while that of SDP decreased to $39.5 \%$ and $27.6 \%$, respectively. The decrease in activity is due to both enzyme inactivation and enzyme leakage after repeated use (Sardar and Gupta 2005). These results indicated that substrate imprinting increases the time of pectinase reutilization, which may be due to tighter cross-linking of enzyme molecules with the chitosan carrier, thus avoiding excessive enzyme leakage during repeated use. These results are consistent with the infrared spectral results showing increased Schiff base content in SDP.

\section{Effect of SDP on Pectin Substances in Whitewater}

The parameter changes of paper making whitewater and the galacturonic acid content were measured. As shown in Table 1, treatment with the three pectinases had almost no effect on the $\mathrm{pH}$ of papermaking whitewater. After FP treatment, the 
conductivity of whitewater increased from 3720 to $3730 \mu \mathrm{S} / \mathrm{cm}$. After the DP and SDP treatments, the conductivity of whitewater decreased, which may be because the conductivity of free pectinase dissolved in whitewater increased the total conductivity of the whitewater. In contrast, DP and SDP can be recycled after whitewater treatment, so that the total conductivity of the whitewater was reduced. Moreover, because SDP is protected by substrate imprinting, it had higher activity than DP. Thus, the conductivity of whitewater after SDP treatment was lower than that after DP treatment (Carrin et al. 2000; Esawy et al. 2013; Chauhan et al. 2015; Ma et al. 2016).

Table 1. Effect of Pectinase Treatment on the Properties of Whitewater

\begin{tabular}{|c|c|c|c|c|}
\hline & $\mathrm{pH}$ & $\begin{array}{c}\text { Conductivity } \\
(\mu \mathrm{S} / \mathrm{cm})\end{array}$ & $\begin{array}{c}\text { Demand for Cation } \\
(\mu \mathrm{eq} / \mathrm{L})\end{array}$ & $\begin{array}{c}\text { Galacturonic Acid } \\
\text { Content }(\mathrm{mg} / \mathrm{L})\end{array}$ \\
\hline Whitewater & 8.20 & 3720 & 905 & 0 \\
\hline FP & 8.22 & 3730 & 655 & 65.4 \\
\hline DP & 8.12 & 3570 & 320 & 84.6 \\
\hline SDP & 8.10 & 3490 & 305 & 93.1 \\
\hline
\end{tabular}

The effect of SDP on controlling pectin in whitewater was the best. SDP treatment reduced the cation demand of whitewater from $905 \mu \mathrm{eq} / \mathrm{L}$ to $305 \mu \mathrm{eq} / \mathrm{L}$. DP treatment reduced the cation demand for whitewater from $905 \mu \mathrm{eq} / \mathrm{L}$ to $320 \mu \mathrm{eq} / \mathrm{L}$.

The galacturonic acid content in whitewater after FP, DP, and SDP treatment was $65.4 \mathrm{mg} / \mathrm{L}, 84.5 \mathrm{mg} / \mathrm{L}$, and $93.1 \mathrm{mg} / \mathrm{L}$, respectively, which was consistent with the decrease of cation demand in whitewater. The galacturonic acid content after SDP treatment was $10 \%$ more than that after DP treatment, indicating that the active center of SDP was protected by substrate imprinting. In addition, imprinting with universal substrate (modified pectin) improved the substrate selection spectrum of the enzyme. Compared with DP, the substrate selection range of SDP was broader, which led to higher catalytic performance of SDP than DP to degrade pectin in whitewater and reduced its demand for cation (Li et al. 2007; Bustamante-Vargas et al. 2015).

\section{CONCLUSIONS}

1. The results show that the enzymatic properties of SDP were significantly improved due to the protective effect of substrate imprinting. Under the same conditions, the relative enzyme activity of SDP compared to DP was increased by $5 \%$ and $15 \%$, respectively, at 35 to $75{ }^{\circ} \mathrm{C}$ and $\mathrm{pH} 4.4$ to 6.5 . SDP was more stable during operation with activity recovery being $39.5 \%$ and $27.6 \%$ after 7 and 8 cycles of use, respectively.

2. The universal imprinting of the substrate improved the catalytic performance of the industrial composite enzyme system, so that the anionic waste in the papermaking whitewater was significantly reduced, and the efficiency of immobilizing pectinase was improved.

3. Overall, the use of a broad-spectrum substrate for imprinting provides a new idea and a new method for immobilizing enzymes. It is proposed that SDP will play a huge role in fruit juice clarification and sewage treatment, and has broad application prospects. 


\section{ACKNOWLEDGMENTS}

The authors are grateful for the financial support of the National Key Research and Development Project, Grant. No. 2017YFB0308402 and the National Natural Science Foundation of China, Grant. Nos. 31570118 and 31800116.

\section{REFERENCES CITED}

Bahrami, A., and Hejazi, P. (2013). "Electrostatic immobilization of pectinase on negatively charged AOT-Fe ${ }_{3} \mathrm{O}_{4}$ nanoparticles," Journal of Molecular Catalysis B: Enzymatic 93, 1-7. DOI: 10.1016/j.molcatb.2013.03.010

Bustamante-Vargas, C. E., Mignoni, M. L., de Oliveira, D., Venquiaruto, L. D., Valduga, E., Toniazzo, G., and Dallago, R. M. (2015). "Synthesis of a hybrid polymerinorganic biomimetic support incorporating in situ pectinase from Aspergillus niger ATCC 9642," Bioprocess and Biosystems Engineering 38(8), 1569-1577. DOI: 10.1007/s00449-015-1399-2

Carrin, M. E., Ceci, L., and Lozano, J. E. (2000). "Effects of pectinase immobilization during hollow fiber ultrafiltration of apple juice," Journal of Food Process Engineering 23(4), 281-298. DOI: 10.1111/j.1745-4530.2000.tb00516.x

Chakraborty, S., Rao, T. J. M., and Goyal, A. (2016). "Immobilization of recombinant pectate lyase from Clostridium thermocellum ATCC-27405 on magnetic nanoparticles for bioscouring of cotton fabric," Biotechnology Progress 33(1), 236-244. DOI: $10.1002 /$ btpr.2379

Chaput, L., Marton, Z., Pineau, P., Domon, L., Tran, V., and Graber, M. (2012). "Enhancing the enantioselectivity of calb by substrate imprinting: A combined experimental and molecular dynamics simulation model study," Journal of Molecular Catalysis B: Enzymatic 84, 55-61. DOI: 10.1016/j.molcatb.2012.04.017

Chauhan, S., Vohra, A., Lakhanpal, A., and Gupta, R. (2015). "Immobilization of commercial pectinase (polygalacturonase) on celite and its application in juice clarification," Journal of Food Processing and Preservation. DOI: 10.1111 jfpp. 12457

Esawy, M. A., Gamal, A. A., Kamel, Z., Ismail, A. M. S., and Abdel-Fattah, A. F. (2013). "Evaluation of free and immobilized Aspergillus niger NRC1ami pectinase applicable in industrial processes," Carbohydrate Polymers 92(2), 1463-1469. DOI: 10.1016/j.carbpol.2012.10.061

Gaio, I., Oro, C. E. D., Graboski, A. M., Bustamante, C., Tres, M. V., Junges, A., Dallago, R. M., Valduga, E., and Furigo Jr, A., (2017). "Liquefied petroleum gas as solvent medium for the treatment of immobilized pectinases," Biocatalysis and Agricultural Biotechnology 11, 108-115. DOI: 10.1016/j.bcab.2017.06.010

Kashyap, D. R., Vohra, P. K., Chopra, S., and Tewari, R. (2001). “Applications of pectinases in the commercial sector: A review," Bioresource Technology 77(3), 215227. DOI: 10.1016/S0960-8524(00)00118-8

Lei, Z., and Bi, S. (2007). "Preparation and properties of immobilized pectinase onto the amphiphilic PS- $b$-PAA diblock copolymers," Journal of Biotechnology 128(1), 112 119. DOI: 10.1016/j.jbiotec.2006.09.002

Lei, Z., Bi, S., Hu, B., and Yang, H. (2007). "Combined magnetic and chemical covalent immobilization of pectinase on composites membranes improves stability and 
activity," Food Chemistry 105(3), 889-896. DOI: 10.1016/j.foodchem.2007.04.045

Li, T., Wang, N., Li, S., Zhao, Q., Guo, M., and Zhang, C. (2007). "Optimization of covalent immobilization of pectinase on sodium alginate support," Biotechnology Letters 29(9), 1413-1416. DOI: 10.1007/s10529-007-9409-3

Liu, K., Li, X. F., Li, X. M., He, B. H., and Zhao, G. L. (2010). "Lowering the cationic demand caused by PGA in papermaking by solute adsorption and immobilized pectinase on chitosan beads," Carbohydrate Polymers 82(3), 648-652. DOI: 10.1016/j.carbpol.2010.05.028

Liu, L., Mao, S. Z., Liu, X. M., Huang, X., Xu, J. Y., and Liu, J. Q., Luo, G. M., and Shen, J. C. (2008). "Functional mimicry of the active site of glutathione peroxidase by glutathione imprinted selenium-containing protein," Biomacromolecules 9(1), 363-368. DOI: $10.1021 / \mathrm{bm} 7008312$

Li, X., Chen, Y., Wang, H., Yao, H., Huang, H., Mai, Y. W., Hu, N., and Zhou, L. (2016). "Inserting Sn nanoparticles into the pores of $\mathrm{TIO}_{2}-\mathrm{X}-\mathrm{C}$ nanofibers by lithiation," Advanced Functional Materials 26(3), 376-383. DOI: 10.1002/adfm.201503711

Ma, X., Wang, D., Yin, M., Lucente, J., and Liu, D. (2016). "Characteristics of pectinase treated with ultrasound both during and after the immobilization process," Ultrasonics Sonochemistry 36, 1-10. DOI: 10.1016/j.ultsonch.2016.10.026

Mendes, A. A., Castro, H. F. D., Rodrigues, D. D. S., Adriano, W. S., Tardioli, P. W., Mammarella, E. J., Giordano Rde, C., and Giordano Rde, L. (2011). "Multipoint covalent immobilization of lipase on chitosan hybrid hydrogels: Influence of the polyelectrolyte complex type and chemical modification on the catalytic properties of the biocatalysts," Journal of Industrial Microbiology \& Biotechnology 38(8), 1055 1066. DOI: 10.1007/s10295-010-0880-9

Ohmiya, K., Terao, C., Shimizu, S., and Kobayashi, T. (1975). "Immobilization of $\beta$ galactosidase by polyacrylamide in the presence of protective agents," Journal of the Agricultural Chemical Society of Japan 39(2), 491-498. DOI:10.1080/00021369.1975.10861617.

Rajdeo, K., Harini, T., Lavanya, K., and Fadnavis, N. W. (2016). "Immobilization of pectinase on reusable polymer support for clarification of apple juice," Food and Bioproducts Processing S0960308516300062. DOI: 10.1016/j.fbp.2016.03.004

Ramirez, H. L., Gómez Brizuela, L., Úbeda-Iranzo, J., Arevalo, M., and Pérez, A. I. B. (2016). "Pectinase immobilization on a chitosan-coated chitin support," Journal of Food Process Engineering 39(1), 97-104. DOI: 10.1111/jfpe.12203

Rehman, H. U., Aman, A., Silipo, A., Qader, S. A. U., Molinaro, A., and Ansari, A. (2013). "Degradation of complex carbohydrate: Immobilization of pectinase from Bacillus licheniformis KIBGE-IB21 using calcium alginate as a support," Food Chemistry 139(1-4), 1081-1086. DOI: 10.1016/j.foodchem.2013.01.069

Rehman, H. U., Nawaz, M. A., Aman, A., Baloch, A. H., and Qader, S. A. U. (2014). "Immobilization of pectinase from Bacillus licheniformis KIBGE-IB21 on chitosan beads for continuous degradation of pectin polymers," Biocatalysis \& Agricultural Biotechnology 3(4), 282-287. DOI: 10.1016/j.bcab.2014.09.003

Sardar, M., and Gupta, M. N. (2005). "Immobilization of tomato pectinase on Con ASeralose 4B by bioaffinity layering," Enzyme and Microbial Technology 37(3), 355359. DOI: j.enzmictec.2005.03.007

Silva, J. A., Macedo, G. A., Gambetta, D. S. R., Giordano, R. L. C., and Goncalves, L. R. B. (2012). "Immobilization of Candida Antarctica lipase b by covalent attachment on 
chitosan-based hydrogels using different support activation strategies," Biochemical Engineering Journal 60, 16-24. DOI: 10.1016/j.bej.2011.09.011

Sojitra, U. V., Nadar, S. S., and Rathod, V. K. (2017). "Immobilization of pectinase onto chitosan magnetic nanoparticles by macromolecular cross-linker," Carbohydrate Polymers 157, 677-685. DOI: 10.1016/j.carbpol.2016.10.018

Wang, B., Cheng, F., Lu, Y., Ge, W., Zhang, M., and Yue, B. (2013). "Immobilization of pectinase from Penicillium oxalicum F67 onto magnetic cornstarch microspheres: characterization and application in juice production," Journal of Molecular Catalysis B: Enzymatic 97, 137-143. DOI: 10.1016/j.molcatb.2013.07.018

Wu, R., He, B. H., Zhao, G. L., Qian, L. Y., and Li, X. F. (2013). "Immobilization of pectinase on oxidized pulp fiber and its application in whitewater treatment," Carbohydrate Polymers 97(2), 523-529. DOI: 10.1016/j.carbpol.2013.05.019

Wu, R., He, B., Zhao, G., and Li, X. (2014). "Immobilization of pectinase on polyethyleneimine-coated pulp fiber for treatment of whitewater from papermaking," Journal of Molecular Catalysis B: Enzymatic 99, 163-168. DOI: 10.1016/j.molcatb.2013.11.007

Article submitted: June 14, 2019; Peer review completed: October 1, 2019; Revised version received: October 6, 2019; Accepted: October 9, 2019; Published: October 11, 2019. DOI: 10.15376/biores.14.4.9364-9374 